Open Access

\title{
Innovativeness, risk-taking, and proactiveness in startups: a case study and conceptual development
}

\section{Gabriel Linton(D)}

Correspondence: gabriel.linton@oru.

Örebro University School of Business, SE-701 82 Örebro, Sweden

\begin{abstract}
Entrepreneurial orientation (EO) research has investigated EO from a unidimensional perspective. By taking the more novel approach of the multidimensional view and focusing on the sub-dimensions, a fine-grained view is achieved. Previous research has often mixed process and outcomes in the conceptualizations of the sub-dimensions of EO. This study argues for making a distinction between process and outcome, which can realize a more nuanced understanding of EO. A qualitative approach is used to achieve a richer understanding of EO. The findings highlight that EO and its subdimensions of innovativeness, risk-taking, and proactiveness can be meaningfully divided between the attributes of process and outcome. The sub-dimensions and the attributes of process and outcome are also argued to vary independently of each other.
\end{abstract}

Keywords: Entrepreneurial orientation, Innovativeness, Risk-taking, Proactiveness, Startups

\section{Introduction}

During the analysis of the empirical data from following two startups and their EO over 2 years, the following observation was made: Drug Advance, a startup developing a revolutionary cancer treatment, involved two innovative and unique technical features. Drug Advance's treatment consisted of a completely new cancer pharmaceutical drug based on a new set of oximes and a unique patch technology to deliver the drug. The patch could be layered with several compounds and offered great precision. The firm had advanced and unique technology that was patented and would thus be labeled as innovative in the entrepreneurial orientation (EO) literature (Covin and Slevin 1989; Miller 1983). However, even though Drug Advance's outcome, in terms of the product, was innovative, the firm did not show much innovativeness through creativity, willingness to change, or novelty in its behavior or processes. For example, even though the firm did not have much capital, it had more of a traditional ambition to conduct most activities, such as manufacturing, within firm borders. This would of course require large upfront investments, which Drug Advance did not have. Nonetheless, Drug Advance showed no signs of creativity and novelty in overcoming these types of difficulties. Thus, the firm had a highly innovative product but showed little creativity and innovativeness in its behavior.

(c) The Author(s). 2019 Open Access This article is distributed under the terms of the Creative Commons Attribution 4.0 International License (http://creativecommons.org/licenses/by/4.0/), which permits unrestricted use, distribution, and reproduction in any medium, provided you give appropriate credit to the original author(s) and the source, provide a link to the Creative Commons license, and indicate if changes were made. 
Arguably, this type of situation is probably not uncommon regarding the EO sub-dimension of, for example, innovativeness. A firm can have more non-innovative behavior and processes and still have innovative outcomes, and vice versa (Garcia and Calantone 2002); nevertheless, the EO construct will most likely not capture this difference, because the construct and the popular Miller/Covin and Slevin (1989) measurement model used in most research focuses mainly on the outcome of innovativeness in the product market (Andersén et al. 2015; Covin and Wales 2012). Two early pioneers of EO research, Covin and Miller (2014, p. 15), state the following about innovativeness: "this ability is typically assessed through the existence of particular innovation process outcomes, such as new product introductions," highlighting the view of innovativeness as measured by outcome.

Thus, the current EO research does not fully capture the innovative behavior and processes; rather, it captures the outcomes, which can be different from the process. In addition, the premise is that the conventional use of the EO construct implies that a firm can be plotted on single unidimensional line between conservative and entrepreneurial, which in turn is reflected in the average of a firm's innovativeness, risk-taking, and proactiveness (Covin and Slevin 1989; Rauch et al. 2009). Another possible way to conceptualize EO is the formative view which contends that each EO sub-dimension may vary independently of each other, which implies that there are different types of EO (Linton and Kask 2017; Lumpkin and Dess 1996). Nevertheless, as the empirical example illustrated above about the sub-dimension of innovativeness, these assumptions about EO may not apply in practice.

In light of this, the paper sets out to answer how the process and outcome attributes of the different EO dimensions interrelate with each other. To be able to answer the research question, an approach that allows for a fine-grained understating of the EO sub-dimensions is needed. A qualitative method is therefore deemed appropriate, which is a novel approach for EO studies (see, e.g., Linton 2016; Riviezzo et al. 2013; Vora et al. 2012). The EO of two technology startups in a commercialization stage is investigated over a 2-year period since previous research has indicated that EO can change over time (Grühn et al. 2017). In this study, the process is considered to be the activities and behaviors of the firm while the product and its features are considered as the outcome. The results of this study suggest that the sub-dimensions can be categorized between process and outcome. Indeed, the fact that there is a difference between process and outcome has been pointed out earlier in terms of innovativeness (Covin and Miller 2014). However, these scholars argue that innovativeness can be assessed through the existence of innovation process outcomes, for example, new products. Furthermore, they argue that triangulating (i.e., mixing) both processes and outcomes of the sub-dimensions strengthens the overall EO construct. The findings in this paper, in contrast, suggest the opposite that the process of a sub-dimension and its outcome do not necessarily have to interrelate. Instead, it is possible that the process of a sub-dimension can be quite different from the outcome of processes.

This study, hence, contributes to theory and practice in a number of ways. First and foremost, the sub-dimensions of EO need to be considered with the attributes of process and outcome as distinct and separate from each other. This is in contrast to current theory, where dimensions referring to process and outcome are mixed (e.g., Covin and Miller 2014). The two firms, which serve as empirical illustrations, show similar tendencies as the example above: a firm can have an innovative product, and still, the processes do not 
have to be innovative, or vice versa. The distinction between process and outcome can also be applied to risk-taking and proactiveness. Second, the sub-dimensions, with each dimension's process and outcome attributes, are found to vary independently of each other. This leads to the possibility that there are many different types or ways of being entrepreneurial. In all, the in-depth study of the sub-dimensions can inform theory by uncovering nuances of the sub-dimensions.

The outline of the study is as follows. First, a review of the EO literature is provided. Second, the research approach and method used with the empirical data is discussed. Third, the emergent framework is presented, and the results of the analysis are reported. The paper continues with a discussion of the results and implications. Last, the section of conclusions includes contributions, managerial implications, and limitations and future research.

\section{Entrepreneurial orientation}

The EO construct has its roots in the strategy-making literature and has a strong connection with McGill University, where researchers such as Khandwalla (e.g., 1976), Mintzberg (e.g., 1973), and Miller (e.g., 1975) were active. The EO construct was first conceptualized by Miller (1983) and later refined by Covin and Slevin $(1989,1991)$. Today, the EO construct is extensively accepted to capture a firm's degree of entrepreneurship (Andersén 2012; Bouchard and Basso 2011; Covin and Wales 2018; Frank et al. 2010; Lumpkin 2011; Wang and Altinay 2012). Over the years, research has highlighted the value of EO in promoting innovation, renewal, and proactive initiatives (Covin and Slevin 1989; Dess and Lumpkin 2005). Centered on Miller's (1983) original conceptualization, researchers generally agree on the three dimensions of EO: innovativeness, risk-taking, and proactiveness (Covin and Wales 2018; Rauch et al. 2009; Wales et al. 2013). Lumpkin and Dess (1996) suggest autonomy and competitive aggressiveness as two more dimensions of the EO construct, but this conceptualization has not been widely adopted (Wales et al. 2013), and it has been argued that the original three-dimension view of EO is best from a conceptual point of view (George and Marino 2011). The present research considers the sub-dimensions to be separate but related (Linton and Kask 2017; Lomberg et al. 2017; Lumpkin and Dess 1996), and therefore, the sub-dimensions will be considered in detail below.

\section{Innovativeness}

Innovativeness reflects the firm's tendency to embrace new technologies or practices and go beyond the current state of the art. This may include new and creative ideas, novelty, and experimentation (Lumpkin and Dess 1996) that might bring new opportunities, novel solutions, or rise to new technology, products, or services (Dess and Lumpkin 2005). Innovativeness is demonstrated with an inclination to challenge the status quo and support new ideas in technology, new product development, and internal processes (Baker and Sinkula 2009). Innovativeness can take several different shapes, for example, technological innovation such as R\&D and engineering, while product-market innovativeness can instead refer to a new market niche, product design, and advertising and promotion (Miller and Friesen 1978). In the EO literature, innovativeness can be described as a range of methods to develop or adopt new activities, services, or products (Vora et al. 2012), which encompasses many of the innovation aspects in the field of innovation (e.g., Garcia and Calantone 
2002; Schumpeter 1934). However, the innovativeness dimension does not go into detail about the different kinds of innovation, such as incremental or radical innovation, or if it is an adoption or generation of innovation (e.g., Pérez-Luño et al. 2011). Nonetheless, the broadness of the EO dimension of innovativeness enables many different areas of innovativeness, such as product, service, and process innovation, to fit into the conceptualization.

\section{Risk-taking}

Different types of risk exist, for example "venturing into the unknown" (personal, social, and psychological), "committing a relatively large portion of assets," and "borrowing heavily" (Baird and Thomas, 1985). Risk can also be related to risk-return and trade-off, the probability of a loss (Lechner and Gudmundsson 2014) or tolerance of uncertainty (Gunawan et al. 2015). Miller and Friesen embrace probability of loss with their definition of risk-taking as "the degree to which managers are willing to make large and risky resource commitments-i.e., those which have a reasonable chance of costly failures" (1978, p. 923). All firms deal with risk at some level; however, the range can be from "safe" risk, which entails low uncertainty and small resource commitments, to high risk, which involves high uncertainty and large resource commitments (Lumpkin and Dess 1996), for example, a new product launch (Naldi et al. 2007).

\section{Proactiveness}

The first-mover advantage was put forward as an advantageous strategy by Lieberman and Montgomery (1988). Lumpkin and Dess (1996) suggest that "initiative by anticipating and pursuing new opportunities and by participating in emerging markets also has become associated with entrepreneurship" (Lumpkin and Dess 1996, p. 146). Miller and Friesen (1978) argue that proactiveness shapes the environment through, for example, new products, technology, and administrative processes in contrast to reacting to the environment. Proactive firms usually have a forward-looking perspective, being able to anticipate and being prepared for the future (Dada and Fogg 2014; Sciascia et al. 2006), and a desire to be pioneers (Wiklund and Shepherd 2005). Miller suggests that proactiveness can be defined as "first to come up with 'proactive' innovations" (1983, p. 771), which suggests focusing more to the speed of innovating and introducing products and services.

\section{The role of the sub-dimensions}

Indeed, the current literature on EO and its sub-dimensions of innovativeness, risk-taking, and proactiveness has been conceptualized to capture a wide range of phenomena for each sub-dimension. This is highlighted by Andersén et al. (2015), who contend that EO needs to be further clarified and that there is value in deconstructing the view of EO, which is often seen at an overall and generic level. This overall view of EO is theoretically modeled as the sub-dimensions reflect the overall $\mathrm{EO}$, and changes in the sub-dimensions are due to a change in the overall EO. In a reflective model, EO can be described as a single level of EO that can range from high to low. The levels of the sub-dimensions are thus expected to covary. In contrast, this study builds upon the formative view of EO (Linton and Kask 2017; Lomberg et al. 2017; Lumpkin and Dess 1996; Pearce II et al. 2010), where the sub-dimensions combine to form a higher order construct. A formative view implies that changes to EO are due to any change in any of the sub-dimensions. Each of the 
sub-dimensions has a unique impact on $\mathrm{EO}$, and these sub-dimensions are also the antecedent to EO. A formative view allows the sub-dimensions to vary, and thereby, EO is not seen as a single variable; instead, different profiles of EO can be established. For example, a profile could have high innovativeness and proactiveness and low risk-taking and still be considered to have relatively high EO. Also with a formative view, Tang et al. (2009) suggest that the sub-dimensions have different relationships with each other and that proactiveness is a key driver of risk-taking and innovativeness. The reflective and formative conceptualizations are both valid constructs, and the choice between them should be made depending on the research question at hand (Covin and Lumpkin 2011; Miller 2011). Miller (2011, p. 880) highlights that each sub-dimension may be interesting to analyze by itself by stating "in some research contexts, the best of both worlds entail analyses that present results for the EO construct and for each of its components" (italics added). Similarly, Lomberg et al. (2017) argue and investigate each sub-dimension of EO and find that the sub-dimensions can have their unique and direct effect to performance.

As the empirical illustration showed in the introduction, current theory, even with a formative view, can still overlook differences between process and outcome within the sub-dimensions. For instance, Pérez-Luño et al. (2011) note the importance of each of the EO sub-dimensions and especially highlight that innovativeness has been defined too broadly without defining if a firm, for example, adopts or generates innovations. In the same fashion, Andersén et al. (2015) argue that the sub-dimensions of EO can be different for different parts of the firm. For example, a firm can be innovative in its marketing while conservative in its product development, and vice versa. In reviewing the innovation literature, Garcia and Calantone (2002) make an important distinction that "it must be emphasized that product innovativeness does not equate to firm innovativeness" (p. 113). The authors thus emphasize that innovative products do not equate to innovative behavior. This is in contrast to Covin and Miller (2014), who contend that including both processes and outcomes in the EO sub-dimensions "triangulate" the sub-dimensions and thereby strengthen the construct. There thus seems to be an ambiguity in the EO research regarding if the process and outcome attributes of the sub-dimensions of innovativeness, risk-taking, and proactiveness either interrelate with each other (Covin and Miller 2014) or act independently of each other (Garcia and Calantone 2002).

\section{Research design}

A longitudinal and qualitative method was deemed appropriate to answer the research question, and very few papers have utilized qualitative methods for entrepreneurial orientation research. In short, qualitative studies are a good choice since they can help to refine existing theories where there have been gaps in the theory (Siggelkow 2007). Furthermore, building theory from qualitative data is presumably done to generate accurate, interesting, and testable theory (Eisenhardt and Graebner 2007). In addition, Miller (2011) proposes to research EO from new perspectives and with other methods than the traditional surveys. Altogether, a qualitative approach is a good fit for the current study.

\section{Data collection}

The qualitative data was collected from two startups in Sweden over a period of 2 years. The two startups were selected from a small sample of startups that the researcher 
investigated. The startups selected for this study were especially interesting since they showed variations in their entrepreneurial behavior (EO) between and within the firms and therefore were theoretically sampled (Eisenhardt and Graebner 2007). Interviews were conducted about every 6 months over a 2-year period, and this resulted in a total of eight interviews with the two selected startups. The potential informants were informed about the research ahead of time in an initial research meeting, where the researchers explained the overall aim of the research and that participation was voluntary. The potential informants were asked if they would want to take part as research subjects, and all asked agreed to participate. The informants and their startups were offered not to be named, both in form of person names in the research findings, and they were also asked for consent to record the interviews, which was agreed upon in all cases. At the time of the first interviews, the firms were established and in a commercialization process. The interviews took place at the site of the startups to allow the context to be observed as well; this enabled the researcher to gain a deeper understating of the startup situation. The interviews were conducted in a semi-open format with the CEO of the firm, and firm-level type questions were in focus. During the first interview, the respondent was asked to provide the background to the formation of the firm and the business idea. Furthermore, they were asked to describe more precisely what activities and processes the firm had been active in thus far and to describe their product. Next, the respondent was asked about the current activities the firm was working on to continue the commercialization process. In subsequent interviews, the respondent was asked what activities had been conducted since the last interview, what activities were currently being undertaken, and any changes to the product. Each interview lasted from 90 to $180 \mathrm{~min}$. Interviews were documented by note-taking and audio transcripts. The audio transcripts were transcribed verbatim, which resulted in a total of 122 pages and over 50,000 words. Additional data were collected directly from the firm, such as business plans, project outlines, and presentations. Information was also gathered from the firms' websites, annual reports, patient descriptions from the Swedish patent database, press releases, and newspaper articles. These additional documents were used to assist in capturing a holistic view of the firms; however, the analysis is centered on the interviews.

\section{Data analysis}

The research process was a constant back and forth between the empirical data and established theory (Eisenhardt 1989). The premise of the research project was initially to explore how EO was exhibited in startups during the commercialization phase. That EO changed over time, and that the sub-dimension can be divided between outcome and process are findings that became apparent in the analysis of the data.

The initial step in the analysis was to code the data according to the entrepreneurial orientation dimensions (innovativeness, risk-taking, and proactiveness) in Nvivo 10 (software developed for qualitative analysis) for the two startups. All the transcripts were read several times, and when something was deemed to be coded as innovativeness, risk-taking or proactiveness, then that bit of text was coded. The coding in Nvivo helped to structure the empirical data and sort the data according to the different dimensions. For the coding process, according to the above categories, the goal was to 
adhere as close as possible to the Miller/Covin and Slevin measurement scale and the theory for each sub-dimension presented above. After all the text had been read and all coding was completed according to the three sub-dimensions, the coded parts could be more closely analyzed. The parts of the text that were not coded as any dimension could be sorted out, which helped reduce the amount of information. It was also possible, for example, to sort the data according to the categories; for instance, all the innovativeness coded parts for one firm were read and analyzed in one document. This was done for each startup and sub-dimension in an attempt to find patterns within the sub-dimensions. Still, after reading these coded bits several times, the coding seemed messy and inconsistent, as there were plenty of ambiguities in the EO sub-dimensions. For example, one firm seemed to exhibit very innovative features but at the same time also exhibit some exceedingly non-innovative features. This was puzzling and unexpected. How could the firms exhibit different features at the same time? The researcher went back to established theory, reread the empirical data and categorizations, and attempted to reanalyze the data. This process was iterated several times. One step to streamline and help make sense of the data was to divide the timeline into two time periods for each firm, and the decision to do so was made about halfway through the analysis. The coded data was divided between an early state and later state of EO, with the first year coded as the early state and the last year coded as the late state. After completing this step, the data became more consistent although there were still ambiguities in the data. The researcher then focused more closely on different types of categories of the EO sub-dimensions, and eventually, two themes started to emerge. The first theme was based on the processes, behaviors, and activities, i.e., how the firm acted in different situations, which is a common way of conceptualizing EO. In contrast, the second theme was the actual outcome, in this case, the specific features of the product offered. Each sub-dimension of innovativeness, risk-taking, and proactiveness was then coded as either process or outcome. After this step, the analysis of the data material became considerably more accurate and consistent.

The emergent framework results in an analysis of innovativeness, risk-taking, and proactiveness, each being divided between the attributes of process and outcome, see Fig. 1. The framework is applied to each firm at an early stage and a later stage, which allows for a total of four different EO states. These four EO states are illustrated with the six dimensions, instead of the original three, and highlights a nuanced view of the sub-dimension. These six dimensions are considered to be independent of each other, which allows a firm, for example, to have an innovative outcome but at the same time have non-innovative processes or vice versa.

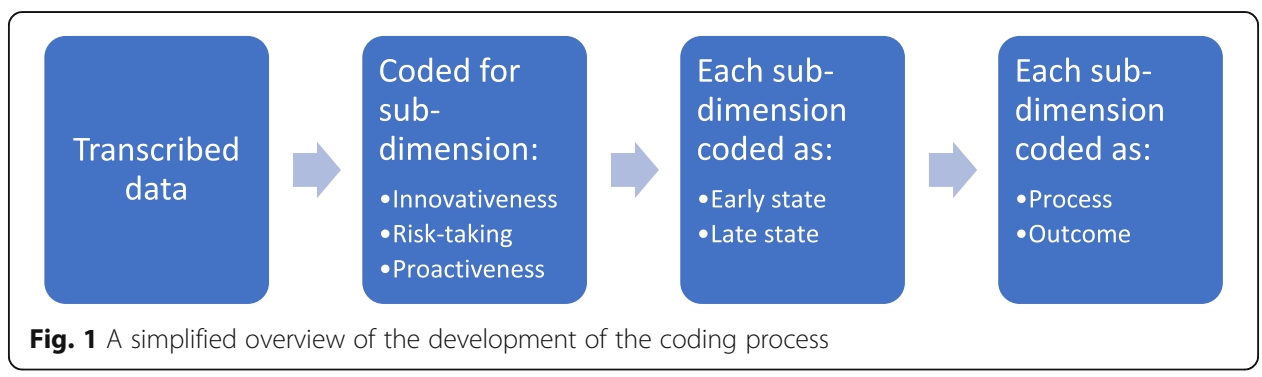




\section{Research findings}

In the following section, the findings are presented according to the emergent framework which was presented above and is a result of the study. The findings are presented according to the emergent framework, where the process and outcome of the sub-dimension are treated separately. Table 1 gives some basic information on the firms, while Tables 2 and 3 provide a summary of the EO of each firm according to the emergent framework. Tables 2 and 3 are similar to Nordqvist et al.'s (2008) qualitative EO reporting, with plus or minus signs assigned depending on how strong the relative indication is made for each EO dimension. One sign (plus or minus) should be considered as somewhat indicative, while two signs are a stronger indication.

\section{Lab Tech}

Lab Tech (Table 1) was founded in 2007 by a university researcher who had come up with a unique technology. The technology would allow the manufacturing of a chip that could improve health diagnostic systems. The chip would have the ability to conduct advanced diagnostics within this electronic chip, instead of more traditional lab machines which are both large in size and expensive to acquire. A single drop of fluid would be used to run numerous parallel assays, which would make it simple to diagnose many medical conditions. Lab Tech's product would be able to perform many of these diagnostics without the use of a central lab, and this would allow for faster test results. The reading unit would be quite simple, while the actual diagnostic technology would be integrated into the chip. The chip would be consumable, and the sale of the consumable chip is where Lab Tech saw profit potential. After about 1 year in a technology incubator, one of the incubator coaches, who possessed previous startup experience as well as a business and engineering education, joined the firm as CEO. This was a move to complement the university researcher with more business experience.

\section{Innovativeness in processes}

Lab Tech seemed to work in an innovative way from the start, which was characterized by, for example, new ideas and creative processes (Dess and Lumpkin 2005). One way Lab Tech showed innovativeness was by having a willingness to change from the status quo and consistently explore new alternatives. For example, at an early stage, the firm outsourced many R\&D activities to several different specialized firms. Later, however, when there were problems getting everything to work, they brought most of the R\&D back in-house, showing that they were able to change the ways they worked. Bringing everything in-house did not work out perfectly. Nonetheless, the firm then actively worked on finding new and creative solutions and new and novel ways of doing things.

Table 1 Description of the firms studied

\begin{tabular}{|c|c|c|c|c|}
\hline Firm & Initial concept & Initial context & Year founded & Founding team \\
\hline Lab Tech & $\begin{array}{l}\text { Developing a method for } \\
\text { the manufacturing of } \\
\text { plastic microfluidic } \\
\text { analysis chips }\end{array}$ & $\begin{array}{l}\text { University spin-off } \\
\text { in a technology } \\
\text { incubator }\end{array}$ & 2007 & $\begin{array}{l}\text { One researcher and one } \\
\text { person with previous } \\
\text { technology startup } \\
\text { experience }\end{array}$ \\
\hline Drug Advance & $\begin{array}{l}\text { Developing a new cancer } \\
\text { treatment drug based on } \\
\text { a new set of oximes }\end{array}$ & $\begin{array}{l}\text { University spin-off } \\
\text { in a regional } \\
\text { incubator }\end{array}$ & 2007 & $\begin{array}{l}\text { One researcher, one medical } \\
\text { doctor, and one person with } \\
\text { a background in business }\end{array}$ \\
\hline
\end{tabular}


Table 2 Summary of Chip Diagnostic's EO

\begin{tabular}{|c|c|c|c|}
\hline \multirow{2}{*}{$\begin{array}{l}\text { Sub-dimension } \\
\text { attribute } \\
\text { Innovativeness } \\
\text { in processes }\end{array}$} & \multicolumn{2}{|c|}{ Early EO state } & Later EO state \\
\hline & + & New ideas and creative way of working & $\begin{array}{l}+ \text { Constant change with creativity and } \\
+ \text { experimentation }\end{array}$ \\
\hline $\begin{array}{l}\text { Innovativeness } \\
\text { in outcome }\end{array}$ & -- & "New" technology not novel or unique & $\begin{array}{l}+\quad \text { Established technology used in new } \\
\text { combinations }\end{array}$ \\
\hline $\begin{array}{l}\text { Risk-taking in } \\
\text { processes }\end{array}$ & $\begin{array}{l}+ \\
+\end{array}$ & $\begin{array}{l}\text { Constant aggressive posture of } \\
\text { risk-taking }\end{array}$ & $\begin{array}{l}+ \text { Constant aggressive posture of risk- } \\
+\quad \text { taking }\end{array}$ \\
\hline $\begin{array}{l}\text { Risk-taking in } \\
\text { outcome }\end{array}$ & & $\begin{array}{l}\text { A product in early development } \\
\text { with high risk }\end{array}$ & - Comprehensible risk of product \\
\hline $\begin{array}{l}\text { Proactiveness } \\
\text { process }\end{array}$ & - & $\begin{array}{l}\text { Reactive leadership without anticipation } \\
\text { of the future }\end{array}$ & $\begin{array}{l}+\quad \text { Leadership actively monitoring and } \\
\text { scanning customer needs }\end{array}$ \\
\hline $\begin{array}{l}\text { Proactiveness } \\
\text { in outcome }\end{array}$ & - & $\begin{array}{l}\text { The product was not first with a solution } \\
\text { in an established market }\end{array}$ & $\begin{array}{l}+\quad \text { Established technology in new } \\
\text { combinations aimed at new market }\end{array}$ \\
\hline
\end{tabular}

The respondent talked about how, after they brought more R\&D in-house and started to run out of money, started to build the chip out of regular office supplies:

...scotch tape, and such things. [We] started to build chips in pure desperation. So, we bought home these things and started, really very simple things; we did not have any money left. All of a sudden, we had something that worked. It was the first time in five years we had a chip [that worked].

This shows a strong orientation toward constantly changing the way to work, which is connected with innovativeness. Experimentation and creativity were also vital parts of the firm's problem solving (Lumpkin and Dess 1996). Lab Tech tried to overcome problems that the firm had in the development of the product with innovativeness in the process, and this innovativeness and creativity increased over time.

\section{Innovativeness in outcome}

Lab Tech started with a manufacturing technology that was unique. Even so, the solutions offered were not as unique as they first thought (Kropp et al. 2008; Miller 1983). In addition, the technology seemed excellent in theory but was almost impossible to get to work on a practical level. The respondent talked about their own initial technology:

... we had then battled to prove this concept for a very long time during the year. But we never got it quite to work, and it was fairly clear that it was largely due to the manufacturing technology that we had developed ourselves... there were other existing machines that could do it, even better, unfortunately.

This shows that the product features were not so innovative, and not being able to get the technology to work on a practical level showed some weaknesses in the product. Over time, the firm decided to drop its own technology that it was developing and instead decided to use available technologies and put them together in new ways. In this way, the product had a few innovative features but was not as fully unique as the firm had first envisioned at the start (Vora et al. 2012). 


\section{Risk-taking in processes}

The firm and its CEO always seemed ready to take on risk without too much hesitation. For example, after the failure of their own technology, which was the foundation of the firm, they still wanted to keep the startup going because they had found a market need that currently was not met. The respondent said:

May it make-or-break! So we took in more capital... it was a little tough. But, but now we are here to see if it holds.

The CEO showed that he and the firm were willing to take on risky projects and processes with unknown outcomes (Lumpkin and Dess 1996; Miller and Friesen 1978). At a later point, he explains that he and the firm want to go all-in and not give up, even though the risk seems high:

I will regret it the rest of my life if we do not fully investigate this now. That is why, in these damned tricky situations, yea, that I still want to see what is around the next corner.

The respondent pointed to the firm's willingness to continue with this idea, even though the risks of the project were high. The firm was clearly taking a business risk by venturing into the unknown where it did not know the probability of success (Dess and Lumpkin 2005). The firm seemed ready to take high risks at all times. This risk-taking was high in the processes for the firm from the beginning, and this high level of risk-taking continued over time.

\section{Risk of outcome}

At first, the risk of the product was quite high. The concept was theoretical but never proven in practice. First, the theoretical concept had to be proven in practice with a prototype. The product was clearly at an early stage in the product development with an unproven technology, which indicates high risk (Dess and Lumpkin 2005). For example, the respondent stated that the firm had tried to calculate the cost of producing the chip:

The calculations I have done are at about $[\mathrm{X}]$ dollar in volume, but then I doubled that. It could be that it has to be doubled again, there is such uncertainty at this stage.

The respondent clearly indicates that the uncertainty was so high that there could be very high variation in the production cost. It was hardly meaningful to make any calculations at all, which indicates one of the high-risk aspects of the product. However, as time went by, the firm gained more and more control over the product development process. Instead of using a new and unproven technology, the firm instead chose to use an already proven technology but used this technology in new ways. This reduced somewhat the risk of the product failing. The respondent indicated later that the product started to become more comprehensible, even if it was, of course, still associated with risk, yet it was lower than earlier in the process.

\section{Proactiveness of process}

At first, it was evident that the proactiveness in processes was low. The firm was not monitoring trends in its field and had difficulty in anticipating the demand from its 
customers (Covin and Slevin 1989). It was clear that the firm did not show a forward-looking perspective in anticipating the future (Lumpkin and Dess 1996). Instead, it showed more reactiveness. For example, the firm was based on a unique technology and the researcher that developed the technology knew of nothing similar in the academic literature. The firm, therefore, assumed that it was the only one with this unique solution. The respondent stated:

I went out and started the marketing. Did this during the spring, went through about 30 companies all around Sweden and Europe and even a few in the US too... But we didn't get the response that we thought we would get... and... then I started and... to do my own market research.

The respondent made clear that they had not done any market research. They had relied on the uniqueness reported in the academic literature and assumed that the solution was unique. Once they started to do market research, they realized that there were other, completely different technologies, which could achieve similar solutions to the same problem. Lab Tech believed that it was the only one with this type of solution, relying too much on academic literature and not so much on market research, which indicates low proactiveness. Nonetheless, the firm did learn from its mistakes and later started to establish more contacts with possible customers, engaging more in finding out about their needs and trying to anticipate the future much more closely (Covin and Slevin 1989).

\section{Proactiveness of outcome}

The proactiveness of the outcome was low to begin with. The technology Lab Tech was developing was found to be difficult to transform from theory into practice, and in addition, there were other technologies that could solve the practical problem in other ways. The respondent stated:

There were technologies that in essence did what our machine could do, that we had constructed at considerable cost. There were plenty of others that had different solutions to it. They were already being produced.

The firm thus failed in being first with the innovation. Even though its technology was unique, there was already a standard set for solving the particular problem, and the firm was not first in offering a solution (Miller 1983). The initial technology was far from being first with a solution and setting a standard ahead of the competition (Dess and Lumpkin 2005). Later, the firm decided to use existing technologies in the product in new ways, combining them to offer a product that offered solutions to a new market segment that did not yet exist. This made the product more proactive. However, as the technology is not completely new, the product does not reach the highest level of proactiveness.

In summary, Lab Tech featured different types of EO over the 2 years (Table 2). Initially, the processes showed risk-taking and some innovativeness but no proactiveness. Nonetheless, the firm had an outcome with high-risk and low innovativeness and proactiveness. Over time, the EO type transformed into processes that increased in innovativeness, maintained a steady high level of risk-taking, and became somewhat 
proactive. Nevertheless, at this time, the outcome showed some innovativeness and proactiveness and less risk.

\section{Drug advance}

Drug Advance (Table 1) was founded in 2007 with the idea of commercializing a new cancer treatment drug. A university researcher had come up with a new group of oximes which could be developed into a pharmaceutical against cancer. This researcher came in contact with a medical doctor, who had many years of experience in treating cancer patients. The medical doctor had an interest in improving the current pharmaceuticals and methods of cancer treatments, and together they started Drug Advance. Soon thereafter, a person with business strategy experience was recruited as the CEO of the firm, and the firm also joined a regional incubator. Early on, the firm also acquired a bioadhesive patch technology which could be used for drug delivery, and the researchers behind this patch also joined the firm.

\section{Innovativeness in processes}

Originally, Drug Advance was a firm with more conservative behaviors than innovative. The business processes seemed to lack innovativeness, such as creativity and openness for change (Lumpkin and Dess 1996); instead, business processes were conducted in a more conventional fashion. Drug Advance seemed to want to operate as a traditional business and retain control within firm borders. There were no signs of experimentation in how to conduct the processes. The firm was trying to secure a large amount of capital to be able to finance the whole operation. For example, the respondent stated:

We have decided that we want to build a firm from the foundation [and up] and be a producer ourselves. And we want to develop it as much as possible and retain control as much as possible.

This is one example that shows the conservative way of thinking. There is a big difference between the capabilities and resources needed for a small R\&D-centered firm with a focus on developing pharmaceuticals and a firm that does everything, including, for example, manufacturing, marketing, and logistics (Zott and Amit 2010). A different

Table 3 Summary of Drug Advance's EO

\begin{tabular}{|c|c|c|}
\hline Sub-dimension & Early EO state & Later EO state \\
\hline $\begin{array}{l}\text { Innovativeness in } \\
\text { processes }\end{array}$ & - Lack of creativity and experimentation & + Some creativity and openness to change \\
\hline $\begin{array}{l}\text { Innovativeness in } \\
\text { outcome }\end{array}$ & $\begin{array}{l}+ \text { Several novel and unique product } \\
+ \text { features }\end{array}$ & - Mainly tried-and-true product features \\
\hline $\begin{array}{l}\text { Risk-taking in } \\
\text { processes }\end{array}$ & $\begin{array}{l}\text { - Calculative and cautious "wait-and-see" } \\
\text { approach to risk-taking }\end{array}$ & $\begin{array}{l}\text { - Calculative and cautious "wait-and-see" } \\
\text { approach to risk-taking }\end{array}$ \\
\hline $\begin{array}{l}\text { Risk-taking in } \\
\text { outcome }\end{array}$ & $\begin{array}{l}+ \text { A product with high-risk and many risky } \\
+ \text { factors }\end{array}$ & $\begin{array}{l}\text { - A product with less risk and less risk } \\
\text { factors }\end{array}$ \\
\hline $\begin{array}{l}\text { Proactiveness in } \\
\text { process }\end{array}$ & + First mover with opportunistic leadership & - Reactive market follower \\
\hline $\begin{array}{l}\text { Proactiveness in } \\
\text { outcome }\end{array}$ & $\begin{array}{l}+ \text { First to introduce several product } \\
+ \text { features }\end{array}$ & - Competing with similar product features \\
\hline
\end{tabular}


approach would be to work with business partners to overcome some resource constraints (Gulati 1999; Kask and Linton 2013). However, Drug Advance seemed determined not to change how it did things and not to think in novel ways about how to conduct its business processes, which can be considered the opposite of innovativeness (Lumpkin and Dess 1996).

However, as time went by, these types of actions and decisions seemed to partly change, and things started to transform. Even though not a complete turnaround, Drug Advance began to challenge its conservative ways of conducting its business processes. It seemed that it was starting to look for somewhat new and novel approaches in its processes. For example, it started to investigate options for working with partner firms in manufacturing, at least initially. When the respondent was asked about the production of the patches he stated:

The production we will not do ourselves. I think one could do it, but it is bothersome and takes a vast amount of time. So we would prefer to have someone that does it on contract.

This example shows that Drug Advance started to change its ways and began to open up for some creativity in the way its business process could be conducted (Dess and Lumpkin 2005). Nevertheless, working with partners is not a breakthrough in innovativeness; it shows that Drug Advance had started to challenge its traditional ways of behavior and started to act with more creativity as well as a willingness to depart from existing practices (Hasche and Linton 2018; Hughes and Morgan 2007; Lumpkin and Dess 1996).

\section{Innovativeness in outcome}

Drug Advance started with a cancer treatment pharmaceutical that proved to "have some very interesting features, compared with the old [current] ones." According to the respondent, these were a whole new group of oximes which were much more efficient in fighting cancer and had unique features in comparison to the existing pharmaceuticals on the market. In addition to having a unique cancer treatment pharmaceutical, it also acquired a patent and recruited the researchers behind the patent for a new patch technology. The respondent explained one feature of the patch:

The point of the patch is that one can control the added pharmaceutical much more precisely than if you have an ointment or a cream.

At this point, the product was both a new cancer drug and a completely new way of delivering the drug. In addition, the patch had superior adhesive features. The product seemed to involve technological leadership in several ways (Covin and Slevin 1991; Miller 1983). Nevertheless, it became more and more stripped of several features as time went by. The respondent stated:

We have decided not to use our own pharmaceutical. We will use the ones that already exist because we found out that there were no patents on the one [pharmaceutical] that is used the most.

Its pharmaceutical would take several years to develop, and therefore, Drug Advance would go with an existing drug to be able to develop the product faster. Yet, even this 
route proved to be too complicated and costly for Drug Advance, at least as a first step. Therefore, it decided to develop only the patch with no pharmaceuticals and sell it as a patch against cold sores. The product would compete with similar patches already existing in the marketplace. Drug Advance's product could stay in place longer than existing cold sore patches. This would be its first product and eventually, once it got up and running, it could add existing pharmaceuticals to it. As a last step, it could even add its own pharmaceutical to the patch. This demonstrates how the product went from being a technology leader with several unique aspects to becoming a product with features similar to those already in the marketplace (Covin and Slevin 1991).

\section{Risk-taking in processes}

Drug Advance's risk-taking can be described as a "wait-and-see" and calculated risk-taking style (Miller 1983; Miller and Friesen 1982). This approach seemed to be stable over the 2-year period as no changes were noticed. This approach can be illustrated, for example, by the reasoning and decisions made around the possible investments in manufacturing equipment. At first, Drug Advance indicated that it needed to trial-run a production machine with its specific mass. The respondent explains:

[It] is tremendously important to know, like, how fast and how much we can get out of the machine. Because it is a cost, of course, to run the machine and to buy the machine, it has to work all of that out, and we will not know that until we have run the mass [for the patch] because different masses have different drying times in the machine... And we do not know the drying time for this mass. And because of this, as soon as we have made a trial run of this mass, then we'll know what output we can get with the machine and then we can calculate if it will pay off or not.

Drug Advance clearly wanted to "wait and see" if the production machine for the patches was effective enough; if it was, then they would go ahead and buy the machine. Nonetheless, later in the process, they still had not bought any manufacturing machines because they now reasoned that they needed a clinical study to ensure that the product worked as promised and that it was safe. In both of these instances, the company took a "wait-and-see" approach to investing as they wanted to calculate their risks. This approach seems to be constant over the 2-year period and relates to its overall approach to risk-taking, which appears to adhere to risk-averse processes via cautious and often incremental behavior (Covin 1991). Vora et al. (2012) suggest that smaller firms might not be able to afford high risk-taking since their capital and ability to pay debts may be limited. Still, even though Drug Advance's risk-taking was constantly low, it did not seem to be due only to capital restrictions; it was more the overall style of the firm.

\section{Risk in outcome}

Drug Advance's product was at first a cancer pharmaceutical, and shortly after, it acquired a patent for the patch for drug delivery. The pharmaceutical and the patch combined made the product risk quite high, as both the pharmaceutical and the patch technology were unproven and required further development (Dess and Lumpkin 2005). However, after unsuccessful investment rounds, Drug Advance realized that the development time was too long, especially for the pharmaceutical drug. The firm 
interpreted the mood of the investors as being interested in the product, but the long development time and the risk were the reasons that only a marginal amount of capital was received. As a result, it started to strip down the product, and eventually, it was only the patch without pharmaceutical substances. The respondent stated:

We would first and foremost continue with the patch development for something that did not require to be regulatorily approved... Patches for the oral cavity is a medical device class one... And because of this, one does not have to go to the Food and Drug Administration to get approval; rather, one gets a CE approval [conformity marking for certain products sold within the European Economic Area].

The CE approval is a much less complicated process than getting a pharmaceutical approved. This, in turn, reduces the risk of the product significantly.

\section{Proactiveness in processes}

Initially, Cancer Patch seemed to portray opportunistic behaviors and decisions. It was trying to initiate new actions that competitors would need to respond to. The ambition was to be a first mover, and with this advantage, it would be able to reap above-average profits (Dess and Lumpkin 2005). Nonetheless, over time, this changed and the proactiveness of the business decisions and actions also changed. At this point, the firm positioned itself as a follower, and the opportunistic behavior decreased. The product would now be launched in a market where Cancer Patch would be following the initiatives of other already established firms (Lumpkin and Dess 1996). This, in turn, would lead to marginal profits, if any. Still, the respondent stated:

We think that the tactic has to be that we have something in the firm that generates money [the empty patch] and then we can take from the profits and reinvest them in developing the next generation's patches.

The posture of Cancer Patch distinctly changed from at first being a proactive first mover then switching to being a follower in the marketplace, which is more related to reactivity (Lumpkin and Dess 2001; Mintzberg 1973).

\section{Proactiveness in outcome}

At first, Drug Advance had a product that showed several proactive features. Initially, the firm was concerned with adding unique features to the product and was able to acquire a patent for a patch that had a unique adhesive and could release pharmaceuticals in layers. This seemed to be a good fit with its cancer treatment drug. At that time, the product was proactive in terms of being the first to present many new features (Miller 1983). Yet, as the product features were reduced, the proactive features of the product also decreased. In the end, all the product features that would have been proactive, that is, being the first product with these features, were stripped away. At this later stage, the product features were similar to the ones already existing in the marketplace and only marginally better. The product lost the unique features that could have shaped the marketplace (Dess and Lumpkin 2005; Lieberman and Montgomery 1988). At this point, Drug Advance planned to introduce a product that would only be marginally 
better in one respect: the adhesiveness of the patch. This is the opposite of being a market leader who is able to quickly innovate and introduce a product with many new features (Miller 1983).

In summary, Drug Advance featured different types of EO over the 2 years (Table 2). At first, the processes did not show innovativeness or risk-taking but some proactiveness, while at the same time, the firm had an innovative, proactive, and high-risk outcome. However, because Drug Advance believed that the risk of the product was too high for investors, it needed to reduce this risk. This was done at the cost of stripping away most of its innovative and proactive features. The firm also changed its way of behavior and actions to become more innovative and less proactive, while risk-taking seemed to stay constant.

\section{Discussion}

The paper sets out to answer the following question: How do process and outcome attributes interrelate with each other in the EO sub-dimensions of innovativeness, risk-taking, and proactiveness? A core insight from the empirical observations is that there is an important difference between process and outcome in the EO sub-dimensions. For example, the illustrative data point to the possibility that innovativeness of outcome and process can be completely different. This is in contrast to Covin and Miller (2014), who suggest that innovativeness can be seen from a process and outcome view. In fact, they even argue that process and outcome can help to "triangulate" innovativeness, thus labeling both outcome and process in a "catchall." This study, in contrast, shows that there can be important differences between process and outcome, and therefore, it can be valuable to investigate these separate from each other, which is more in line with the innovation literature, which points to considerable differences between outcome and process (Garcia and Calantone 2002). The empirical data in this study illustrate that innovative processes and outcomes are salient attributes. The process and outcome attributes can be related, but by making a distinction between them and treating them separately, we can arrive at a more clarified understanding of innovativeness. For example, the results show that a firm can act with high innovativeness in processes and actions and still have an outcome that is not very innovative.

The fact that innovativeness needs further conceptualization has been established in the literature. For example, Zellweger and Sieger (2012) found that the traditional EO approach to innovativeness did not capture internal aspects of innovativeness. In a similar vein, Vora et al. (2012) suggest that smaller scale and internal aspects are not taken into consideration with the traditional conceptualization of innovativeness in EO. This study supports these notions and suggests that the innovativeness sub-dimension of EO needs to be carefully conceptualized as the attributes of process and outcome are salient. Innovativeness in processes would then be able to capture internal aspects of innovativeness, which is more in line with Lumpkin and Dess's (1996) definition of innovativeness, which includes creativity, experimentation, openness to change, and novelty. On the other hand, innovativeness of outcome would capture the external types of innovativeness, which is more in line with Miller's (1983) definition of innovativeness as "product-market innovativeness" (p.771) and Covin and Slevin's (1989) definition, which added the technological part and defined innovativeness as 
"technological and product innovation" (p.79). Generally, EO researchers have focused on innovativeness in the launch of new products (Pérez-Luño et al. 2011), while internal processes have been peripheral (Vora et al. 2012).

Moreover, Covin and Miller (2014) only discuss the innovativeness sub-dimension from a process and outcome perspective. This study, in contrast, shows that risk-taking and proactiveness can also be meaningfully divided into process and outcome and thereby increase our understanding of the different sub-dimensions (cf. Vora et al. 2012). For example, the analysis shows that a firm can act with high risk-taking in processes and still the risk in the outcome is low. In EO research, risk-taking seems to discuss mainly the process aspects of taking risks, e.g., borrowing heavily and taking on risky ventures (Covin and Slevin 1989; Lumpkin and Dess 1996; Miller 1983). Nonetheless, in Lumpkin and Dess' (1996) definition, one can find parts of an outcome perspective with wordings such as "bringing new products into new markets" (p. 145). Furthermore, the empirical illustrations show that proactiveness can be different for process and outcome as well. The proactiveness definition by Lumpkin and Dess (1996) can be seen more from a process perspective with wordings such as "anticipation and acting on future needs" and "forward-looking perspective" (p.146) while Miller (1983) defined proactiveness as being first with innovations, which relates to the outcome of being proactive.

Based on the findings discussed above, a framework is proposed. The framework highlights that the process and outcome attributes for the sub-dimensions can be distinctly different, and therefore, it can be valuable to treat process and outcome separate. The early conceptualizations of the sub-dimensions seem to combine both process and outcome or only consider process or outcome. Therefore, the following proposition is suggested:

Proposition one: Process and outcome are salient attributes for the EO sub-dimensions of innovativeness, risk-taking and proactiveness

Furthermore, for both firms analyzed in this study, it appears that the process and outcome aspects of the EO sub-dimensions differ in many instances, which is an indication that they are independent: that is, that the process and outcome attributes for the sub-dimensions do not necessarily have to covary. The results add to the multidimensional view of EO by indicating that not only may the traditionally defined sub-dimensions vary independently (Lumpkin and Dess 1996), but also the process and outcome attributes of each sub-dimension.

Proposition two: The sub-dimensions of innovativeness, risk-taking, and proactiveness and the process and outcome attributes of these subdimensions may vary independently of each other

\section{Implications}

This paper argues that it is important and valuable to distinguish between process and outcome attributes of EO, as shown in Fig. 2. Based on the results, it is argued that the sub-dimensions are currently too broadly defined. If a variable is too broadly defined, it is possible that noise in the cause-effect relationship distorts the effects, leaving 


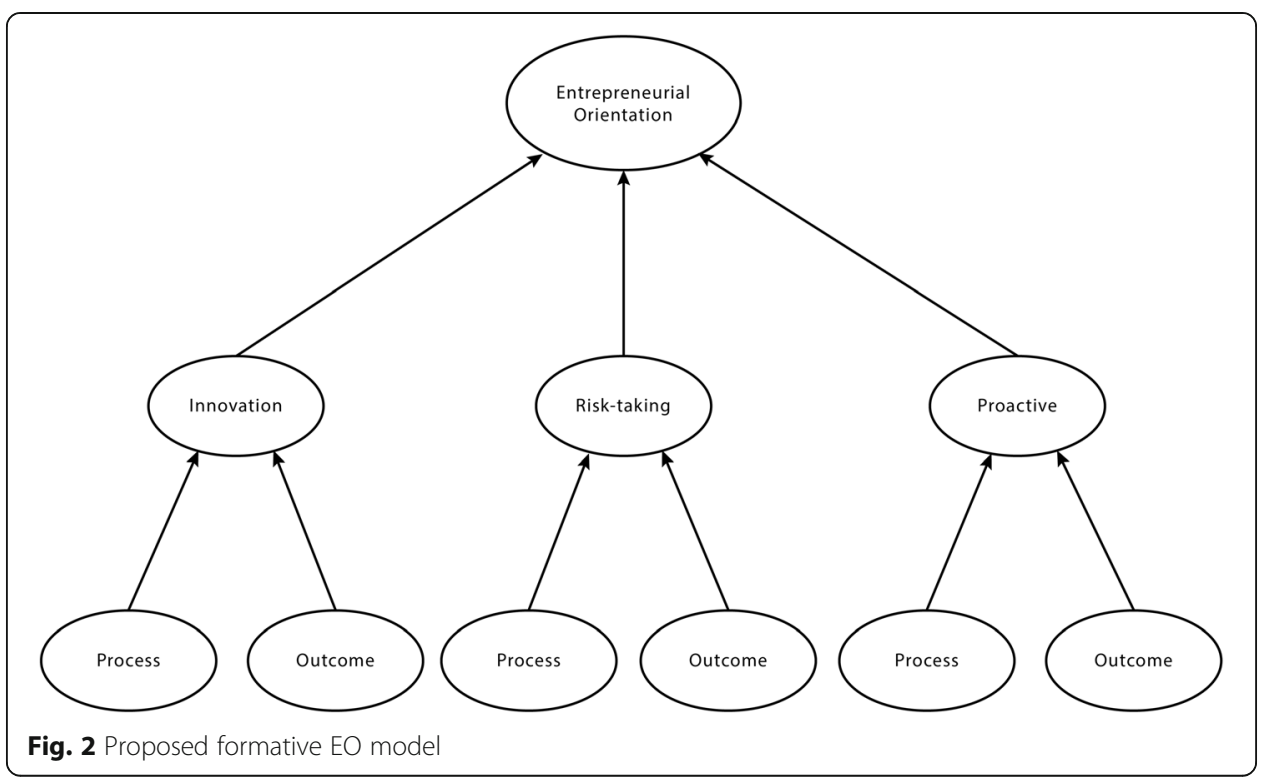

researchers puzzled about the relationship. Too broad variable definitions can also lead to that effects that are not theorized will be detected and might then be wrongly interpreted (Luft and Shields 2003). As the results indicate that the process and outcome attributes of the EO sub-dimensions are salient and may vary independently, these different attributes can affect the sub-dimensions differently. In addition, the process and outcome attributes can have different antecedents. By investigating the process and outcome attributes separately, we can build an understanding of which antecedents are related to process and outcome, respectively. Altogether, if process and outcome are grouped together, there is a possibility that they mask each other's effect and they might have different antecedents (Fig. 2).

Moreover, when conceptualizing EO, it can be of importance to also consider how EO is operationalized as this study suggests that process and outcome attributes are not necessarily linked. For example, when measuring EO, items of both process and outcome for all the sub-dimensions should be included and may be treated separately. EO researchers have a tendency of adhering to the same measuring scale (Covin and Slevin 1989; Miller 1983) that was developed over 30 years ago. It might be time to renew our measurement scales (Miller 2011) that treat process and outcome separately.

\section{Conclusion}

The aim of the paper is to investigate how the process and outcome attributes of the EO sub-dimensions of innovativeness, risk-taking, and proactiveness may interrelate with each other. Two important theoretical contributions to the EO research are made. First, it is highlighted that researchers need to carefully consider that process and outcome are salient for each of the sub-dimension of EO. Second, the sub-dimensions with the process and outcome attributes of each sub-dimension may vary independently of each other. Thus, as process and outcome can be distinctly different and vary independently of each other, researchers are urged to carefully conceptualize and 
operationalize the sub-dimensions and not necessarily bundle process and outcome together. This can include, for example, new measurement scales that clearly separate process and outcomes.

Practical implications for managers include that there can be many different types of entrepreneurial activities and outcomes. To keep an entrepreneurial advantage, managers should consider which processes and outcomes are suitable for the context of the specific firm, instead of necessarily focusing on an "overall" and generic entrepreneurial orientation. Moreover, the deconstruction of the EO concept offers a perspective where it becomes more tangible for managers in contrast to an overall EO, which might be more intangible and difficult to grasp.

\section{Limitations and future research}

This study was conducted in the specific context of innovative startups, and the transferability of the findings to other types of firms should not be taken for granted, although the theoretical reasoning and conclusions are not specific to this context. Nonetheless, this requires investigation of future research; for example, the propositions could be investigated in established medium and large-sized firms. Another possible limitation is that this study has only considered products as an outcome. The outcome might not necessarily be products or services, and future research is encouraged to investigate other types of outcomes. Yet another fruitful area for advancement is our understanding of how the different sub-dimensions can combine together in different types of entrepreneurship. In sum, although much progress has been made with the EO construct, there are still opportunities for future development and refinement of the core construct.

Abbreviations

CEO: Chief Executive Officer; EO: Entrepreneurial orientation; R\&D: Research and development

Acknowledgements

The author appreciates M. Comstock's contribution as language editor, J. Gerdin, C. Öberg and L. Höglund for helpful comments on an earlier version and now retired $\mathrm{H}$. Packard for the everyday support at the office.

Funding

No funding was provided for the study.

Availability of data and materials

Only partial availability of the data is possible due to the anonymity of the respondents and only for reasonable requests.

Author's contributions

$G L$, the sole author of this article, has conducted the whole study including collecting empirical data; constructing the design of the study, the theoretical background, and the analysis; and writing up of the article. The author read and approved the final manuscript.

Competing interests

The author declares that he has no competing interests.

\section{Publisher's Note}

Springer Nature remains neutral with regard to jurisdictional claims in published maps and institutional affiliations.

Received: 14 September 2018 Accepted: 15 January 2019

Published online: 31 January 2019

References

Andersén, J. (2012). A resource-based taxonomy of manufacturing MSMEs. International Journal of Entrepreneurial Behavior \& Research, 18(1), 98-122.

Andersén, J., Ljungkvist, T., \& Svensson, L. (2015). Entrepreneurially oriented in what? A business model approach to entrepreneurship. Journal of Small Business and Enterprise Development, 22(3), 433-449. 
Baird, I. S., \& Thomas, H. (1985). Toward a contingency model of strategic risk taking. Academy of management Review, 10(2), 230-243.

Baker, W. E., \& Sinkula, J. M. (2009). The complementary effects of market orientation and entrepreneurial orientation on profitability in small businesses*. Journal of Small Business Management, 47(4), 443-464.

Bouchard, V., \& Basso, O. (2011). Exploring the links between entrepreneurial orientation and intrapreneurship in SMEs. Journal of Small Business and Enterprise Development, 18(2), 219-231.

Covin, J. G. (1991). Entrepreneurial versus conservative firms: a comparison of strategies and performance. Journal of Management Studies, 28(5), 439-462.

Covin, J. G., \& Lumpkin, G. T. (2011). Entrepreneurial orientation theory and research: reflections on a needed construct. Entrepreneurship Theory and Practice, 35(5), 855-872.

Covin, J. G., \& Miller, D. (2014). International entrepreneurial orientation: conceptual considerations, research themes, measurement issues, and future research directions. Entrepreneurship Theory and Practice, 38(1), 11-44.

Covin, J. G., \& Slevin, D. P. (1989). Strategic management of small firms in hostile and benign environments. Strategic Management Journal, 10(1), 75-87.

Covin, J. G., \& Slevin, D. P. (1991). A conceptual model of entrepreneurship as firm behavior. Entrepreneurship: Theory and Practice, 16(1), 7-25.

Covin, J. G., \& Wales, W. J. (2012). The measurement of entrepreneurial orientation. Entrepreneurship Theory and Practice, 36(4), 677-702

Covin, J. G., \& Wales, W. J. (2018). Crafting High-Impact Entrepreneurial Orientation Research: Some Suggested Guidelines. Entrepreneurship Theory and Practice. Entrepreneurship Theory and Practice 43(1), 3-18.

Dada, O., \& Fogg, H. (2014). Organizational learning, entrepreneurial orientation, and the role of university engagement in SMEs. International Small Business Journal Vol. advance online publication. Available at: https://doi.org/10.1177/ 0266242614542852

Dess, G. G., \& Lumpkin, G. T. (2005). The role of entrepreneurial orientation in stimulating effective corporate entrepreneurship. Academy of Management Executive, 19(1), 147-156.

Eisenhardt, K. M. (1989). Building theories from case study research. Academy of Management Review, 14(4), 532-550.

Eisenhardt, K. M., \& Graebner, M. E. (2007). Theory building from cases: opportunities and challenges. Academy of Management Journal, 50(1), 25-32.

Frank, H., Kessler, A., \& Fink, M. (2010). Entrepreneurial orientation and business performance - a replication study** Schmalenbach Business Review : ZFBF, 62(2), 175-198.

Garcia, R., \& Calantone, R. (2002). A critical look at technological innovation typology and innovativeness terminology: a literature review. Journal of Product Innovation Management, 19(2), 110-132.

George, B. A., \& Marino, L. (2011). The epistemology of entrepreneurial orientation: conceptual formation, modeling, and operationalization. Entrepreneurship Theory and Practice, 35(5), 989-1024.

Grühn, B., Strese, S., Flatten, T. C., Jaeger, N. A., \& Brettel, M. (2017). Temporal change patterns of entrepreneurial orientation: A longitudinal investigation of CEO successions. Entrepreneurship Theory and Practice, 41(4), 591-619.

Gulati, R. (1999). Network location and learning: The influence of network resources and firm capabilities on alliance formation. Strategic Management Journal, 20, 397-420.

Gunawan, T., Jacob, J., \& Duysters, G. (2016). International Entrepreneurship Management Journal, 12:575. https://doi.org/10. 1007/s11365-014-0355-y.

Hasche, N., \& Linton, G. (2018). The value of failed relationships for the development of a Medtech start-up. Journal of Small Business \& Entrepreneurship, 30(1), 97-119.

Hughes, M., \& Morgan, R. E. (2007). Deconstructing the relationship between entrepreneurial orientation and business performance at the embryonic stage of firm growth. Industrial Marketing Management, 36(5), 651-661.

Kask, J., \& Linton, G. (2013). Business mating: when start-ups get it right. Journal of Small Business \& Entrepreneurship, 26(5), 511-536.

Khandwalla, P. N. (1976). Some top management styles, their context and performance. Organization and Administrative Sciences, 7(4), 21-51.

Kropp, F., Lindsay, N. J., \& Shoham, A. (2008). Entrepreneurial orientation and international entrepreneurial business venture startup. International Journal of Entrepreneurial Behavior \& Research, 14(2), 102-117.

Lechner, C., \& Gudmundsson, S. V. (2014). Entrepreneurial orientation, firm strategy and small firm performance. International Small Business Journal, 32(1), 36-60.

Lieberman, M. B., \& Montgomery, D. B. (1988). First mover advantages. Strategic Management Journal, 9, 41-58.

Linton, G. (2016). Entrepreneurial orientation : reflections from a contingency perspective. Örebro: Örebro university.

Linton, G., \& Kask, J. (2017). Configurations of entrepreneurial orientation and competitive strategy for high performance. Journal of Business Research, 70, 168-176.

Lomberg, C., Urbig, D., Stöckmann, C., Marino, L. D., \& Dickson, P. H. (2017). Entrepreneurial orientation: the dimensions' shared effects in explaining firm performance. Entrepreneurship Theory and Practice, 41(6), 973-998.

Luft, J., \& Shields, M. D. (2003). Mapping management accounting: graphics and guidelines for theory-consistent empirical research. Accounting, Organizations and Society, 28(2-3), 169-249.

Lumpkin, G. T. (2011). From legitimacy to impact: moving the field forward by asking how entrepreneurship informs life. Strategic Entrepreneurship Journal, 5(1), 3-9.

Lumpkin, G. T., \& Dess, G. G. (1996). Clarifying the entrepreneurial orientation construct and linking it to performance. The Academy of Management Review, 21, 135-172.

Lumpkin, G. T., \& Dess, G. G. (2001). Linking two dimensions of entrepreneurial orientation to firm performance: the moderating role of environment and industry life cycle. Journal of Business Venturing, 16(5), 429-451.

Miller, D. (1975). Towards a contingency theory of strategy formulation. Academy of Management Proceedings, 1975(1), 64-66.

Miller, D. (1983). The correlates of entrepreneurship in three types of firms. Management Science, 29, 770-791.

Miller, D. (2011). Miller (1983) revisited: a reflection on EO research and some suggestions for the future. Entrepreneurship Theory and Practice, 35(5), 873-894.

Miller, D., \& Friesen, P. H. (1978). Archetypes of strategy formulation. Management Science, 24(9), 921-933.

Miller, D., \& Friesen, P. H. (1982). Innovation in conservative and entrepreneurial firms: two models of strategic momentum. Strategic Management Journal, 3, 1-25. 
Mintzberg, H. (1973). Strategy-making in three modes. California Management Review, 16(2), 44-53.

Naldi, L., Nordqvist, M., Sjöberg, K., \& Wiklund, J. (2007). Entrepreneurial orientation, risk taking, and performance in family firms. Family Business Review, 20(1), 33-47.

Nordqvist, M., Habbershon, T. G., \& Melin, L. (2008). Transgenerational entrepreneurship: exploring entrepreneurial orientation in family firms, In Landström, H., Crijns, H., Laveren, E. and Smallbone, D. (Eds.). Entrepreneurship, Sustainable Growth and Performance: Frontiers in European Entrepreneurship Research, p. 93.

Pearce, J. A., II, Fritz, D. A., \& Davis, P. S. (2010). Entrepreneurial orientation and the performance of religious congregations as predicted by rational choice theory. Entrepreneurship Theory and Practice, 34(1), 219-248.

Pérez-Luño, A., Wiklund, J., \& Cabrera, R. V. (2011). The dual nature of innovative activity: how entrepreneurial orientation influences innovation generation and adoption. Journal of Business Venturing, 26(5), 555-571.

Rauch, A., Wiklund, J., Lumpkin, G. t., \& Frese, M. (2009). Entrepreneurial orientation and business performance: an assessment of past research and suggestions for the future. Entrepreneurship Theory and Practice, 33(3), 761-787.

Riviezzo, A., Napolitano, M. R., \& Garofano, A. (2013). Entrepreneurial orientation and market orientation in SMEs: an explorative study, in Fayolle, A., Kyr., P., Mets, T. \& Venesaar, U. (Eds.). Conceptual Richness and Methodological Diversity in Entrepreneurship Research, p. 197. Cheltenham: Edward Elgar.

Schumpeter, J. A. (1934). The theory of economic development: An inquiry into profits, capital, credit, interest, and the business cycle. Cambridge Mass: Harvard Business Press.

Sciascia, S., Naldi, L., \& Hunter, E. (2006). Market orientation as determinant of entrepreneurship: an empirical investigation on SMEs. The International Entrepreneurship and Management Journal, 2(1), 21-38.

Siggelkow, N. (2007). Persuasion with case studies. Academy of Management Journal, 50(1), 20-24

Tang, Z., Kreiser, P. M., Marino, L., Dickson, P., \& Weaver, K. M. (2009). A hierarchical perspective of the dimensions of entrepreneurial orientation. International Entrepreneurship and Management Journal, 5(2), 181-201.

Vora, D., Vora, J., \& Polley, D. (2012). Applying entrepreneurial orientation to a medium sized firm. International Journal of Entrepreneurial Behavior \& Research, 18(3), 352-379.

Wales, W. J., Gupta, V. K., \& Mousa, F.-T. (2013). Empirical research on entrepreneurial orientation: an assessment and suggestions for future research. International Small Business Journal, 31(4), 357-383.

Wang, C. L., \& Altinay, L. (2012). Social embeddedness, entrepreneurial orientation and firm growth in ethnic minority small businesses in the UK. International Small Business Journal, 30(1), 3-23.

Wiklund, J., \& Shepherd, D. (2005). Entrepreneurial orientation and small business performance: a configurational approach. Journal of Business Venturing, 20(1), 71-91.

Zellweger, T., \& Sieger, P. (2012). Entrepreneurial orientation in long-lived family firms. Small Business Economics, 38(1), 67-84

Zott, C., \& Amit, R. (2010). Business model design: an activity system perspective. Long Range Planning, 43, 216-226.

\section{Submit your manuscript to a SpringerOpen ${ }^{\circ}$ journal and benefit from:}

- Convenient online submission

- Rigorous peer review

- Open access: articles freely available online

High visibility within the field

- Retaining the copyright to your article

Submit your next manuscript at $\boldsymbol{\sim}$ springeropen.com 